\title{
RESENHA/REVIWES
}

LEMOS, Patrícia Faga Iglecias. Meio ambiente e responsabilidade civil do proprietário: análise do nexo causal. 2. ed. rev. atual. e ampl. São Paulo: Editora Revista dos Tribunais, 2012.

\section{MEIO AMBIENTE E RESPONSABILIDADE CIVIL DO PROPRIETÁRIO: ANÁLISE DO NEXO CAUSAL}

\section{ENVIRONMENT AND LIABILITY OWNER: ANALYSIS OF CAUSAL LINK}

\section{Larissa Gabrielle Braga e Silva ${ }^{1}$}

Como citar: SILVA, Larissa Gabrielle Braga e. Meio ambiente e responsabilidade civil do proprietário: análise do nexo causal. Scientia Iuris, Londrina, v. 20, n. 3, p.330-337, nov. 2016. DOI: 10.5433/2178-8189.2016v20n3p330. ISSN: 2178-8189.

A pesquisa desenvolvida pela autora tem como objetivo analisar a responsabilidade civil do proprietário e sua relação com o meio ambiente abordando aspectos afetos ao nexo de causalidade.

A obra é dividida em três partes, na primeira intitulada propriedade e seu fundamento constitucional, a autora aborda acerca da propriedade enaltecendo a normatividade do artigo 1228 do Código

1 Mestranda pela Escola Superior Dom Helder Câmara (ESDHC). Graduada em Direito pela Pontifícia Universidade Católica de Minas Gerais (PUC-MG).

E-mail: larissabragadv@gmail.com. 
Civil e alinhavando-a ao direito fundamental ao meio ambiente. Descreve também acerca dos elementos constitutivos do direito de propriedade e suas limitações.

Ainda no capítulo I, a autora discorre sobre os princípios de proteção socioambiental, descreve o meio ambiente ecologicamente equilibrado como direito fundamental e trata dos princípios da ubiquidade, do desenvolvimento sustentável, da participação, do poluidor-pagador, da prevenção, precaução, da função socioambiental da propriedade e do princípio da solidariedade intergeracional.

$\mathrm{Na}$ segunda parte a autora discorre acerca da função socioambiental da propriedade e do meio ambiente ecologicamente equilibrado. Ainda dedica-se ao estudo do meio ambiente ecologicamente equilibrado e direito de propriedade, abordando o bem socioambiental, sua propriedade e o meio ambiente ecologicamente equilibrado como direito fundamental de terceira geração, aborda também a propriedade com incidência em áreas de preservação permanente e reserva legal. $\mathrm{Na}$ parte terceira a autora trata do dano ambiental, do nexo de causalidade e da responsabilidade civil do proprietário. A obra é escrita em 208 páginas.

A propriedade é descrita a partir de sua evolução histórica e atualmente se aproxima do seu caráter social e não absoluto. $\mathrm{O}$ meio ambiente é considerado bem de interesse difuso. O exercício do direito de propriedade envolve a apropriação de bens, preservando-se a utilização do bem para os demais. $\mathrm{O}$ direito ao meio ambiente equilibrado é direito fundamental de terceira geração, e diz sobre o direito à vida.

A autora aponta que deve haver um ponto de convergência entre o direito de propriedade e o direito ao meio ambiente ecologicamente equilibrado. Atualmente, o direito de propriedade não é mais absoluto o que impõe ao proprietário limitações civis, penais, administrativas, 
ambientais e constitucionais. A função socioambiental da propriedade trabalha para conformar seus elementos e fins para os interesses sociais e ambientais.

Os princípios são abordados de forma clara e sucinta e correspondem às bases de sustentação do direito ao meio ambiente sadio e equilibrado. O princípio da dignidade da pessoa humana constitui o núcleo dos direitos humanos que contempla os direitos de igualdade, fraternidade e liberdade. $\mathrm{O}$ direito ambiental assume postura de proteção à vida, o que significa dizer que todos os direitos devem obedecer aos primados da proteção ambiental.

A autora ainda destaca que o princípio da participação apresenta relevância na atuação do proprietário no tocante ao uso do bem ambiental em consonância com a proteção do meio ambiente para as presentes e futuras gerações.

Enaltece o princípio do desenvolvimento sustentável associado ao exercício do direito de propriedade, pois o bem ambiental é o mesmo a propiciar o desenvolvimento econômico, social, cultural, político e que também garante a manutenção da sadia qualidade de vida.

O princípio do poluidor-pagador impõe ao responsável pela utilização do bem a responsabilidade pelos custos de prevenção de eventuais danos.

Destaca a responsabilidade civil ambiental e pontua que a função desta responsabilidade é cumprida quando se percebe que é mais barato prevenir os danos do que repará-los. No direito brasileiro prevalece a responsabilização objetiva pelo risco integral.

O princípio da precaução é adotado diante da incerteza científica da ocorrência do dano ao meio ambiente. Por sua vez, o princípio da equidade intergeracional exige um comportamento ético de utilização 
do meio ambiente o que implica na importância da educação ambiental cujo escopo é a proteção das presentes e futuras gerações, visando uma mudança de comportamento da sociedade.

Acerca da propriedade a autora afirma que esta possui função social e função ambiental e que o descumprimento destas funções não esvazia a propriedade de seu conteúdo mínimo. A função socioambiental implica em um poder-dever que pode ser sancionado pela ordem jurídica. Dessa forma, o exercício da propriedade deve se ajustar às finalidades sociais e ambientais o que implica na possibilidade de se imputar condutas positivas ou negativas ao proprietário.

O direito ambiental apresenta titularidade difusa. A cidade também deve cumprir sua função socioambiental o que garantirá sadia qualidade de vida, balizada pelo estatuto da cidade o que permite o surgimento das cidades sustentáveis, o que determina seu crescimento ordenado. O escopo do direito ambiental é garantir a todos uma existência digna e a propriedade, neste sentido, assume posição de abonar a realização dos interesses individuais, sociais e ambientais.

A revolução industrial marca um período de intensa interferência do homem no meio ambiente, porém, seus efeitos só são constatados a partir do século XX. O reconhecimento do direito ao meio ambiente ecologicamente equilibrado como direito fundamental cria deveres de preservação para o Estado e para a sociedade.

A noção de meio ambiente contempla os aspectos natural, artificial, laboral e cultural e se forma pelo conjunto de interações que condiciona à vida. Os bens ambientais, assim, são aqueles que têm relevância para a sadia qualidade de vida, ínsita, pois, a obrigação de preservação das riquezas naturais. Assim, no bojo das questões atinentes à propriedade, haverá dois conteúdos um de ordem individual (em relação 
ao proprietário) e outro de ordem social (em relação aos titulares do interesse difuso).

O proprietário pode ser compelido a ter comportamentos ativos e passivos para a efetiva proteção da propriedade em razão de sua característica socioambiental.

O dano ao meio ambiente é considerado como um dano a um interesse difuso, quando atinge interesse de particular é chamado de dano reflexo. $\mathrm{O}$ dano ao meio ambiente pode se consolidar patrimonialmente ou extrapatrimonialmente. Quando atinge interesse difuso é objetivo, é subjetivo quando atinge interesse individual.

A reparação do dano extrapatrimonial prefere à restauração do bem degradado e só ocorre dano depois de ultrapassado o limite de tolerabilidade da agressão. Para se mensurar esta tolerabilidade é necessária análise técnica multidisciplinar. Mesmo havendo licença e a atividade sendo lícita não será afastado o dever de recomposição do bem.

Em decorrência do princípio de informação ambiental, na alienação do bem, o proprietário deve ser obrigado a informar eventual utilização que possa implicar danos ao meio ambiente.

A responsabilização ambiental é objetiva dispensando-se a análise do dolo e culpa. Para haver a reparação é necessária a ocorrência do dano e do nexo de causalidade. A autora defende que para haver responsabilização do causador do dano ao meio ambiente deve haver prova do nexo de causalidade. Passa, então, a apontar as teorias do nexo. Diz que a teoria da equivalência das condições é aquela em que todas as condições são equivalentes para a produção do resultado danoso. Esta teoria não é apta para a responsabilidade ambiental, pois esta admite exclusão de responsabilidade quando o agente demonstra que o dano ocorreria mesmo sem a sua atuação, haja vista ser a responsabilidade 
civil ambiental objetiva e solidária.

A teoria da causalidade adequada é aquela em que a causa deve ser apta para atingir um resultado, o que também pode implicar exclusão da responsabilidade pelas concausas.

As teorias desenvolvidas neste sentido não são adequadas porque afastam a necessidade do nexo de causalidade trabalhando com meras probabilidades para determinar a reparação do dano. A autora é veemente quando afirma a necessidade da prova do nexo de causalidade como condição jurídica para se efetivar a proteção do meio ambiente ecologicamente equilibrado. Advoga a aplicação na seara do ambiente da teoria do escopo da norma jurídica violada, tanto na responsabilidade civil geral como nos casos de descumprimento da função socioambiental da propriedade.

A autora defende também a possibilidade de inversão do ônus da prova e das presunções de causalidade quando, por exemplo, há várias fontes emissoras, ou grande distância entre o local da ação ou emissão e o resultado danoso.

O direito à informação ambiental é importante instrumento facilitador da prova do nexo de causalidade. É cumprido, por exemplo, quando se averba na matrícula do imóvel a informação da existência de área contaminada, sem se descurar que o alienante tem o dever de informar sobre a utilização do bem e dos perigos desta advindos.

A nosso sentir, a autora tem razão quando afirma da necessidade de prova do nexo de causalidade para se aplicar a responsabilidade civil, admitindo as presunções de causalidade em alguns casos específicos. $\mathrm{O}$ direito de propriedade, hoje, não apresenta um caráter absoluto e deve ser exercido com limitações e com respeito aos impositivos da função socioambiental. Diante do descumprimento destes deveres deve incidir 
os consectários da responsabilidade civil, sempre, prevalecendo a reparação. O bem então não integra somente o patrimônio do particular, ao contrário, insere-se num complexo de comunidade haja vista pertencer à característica de direito difuso, ínsito ao direito ambiental.

A principiologia apresentada denota a fundamentação da responsabilidade civil e do próprio Direito Ambiental, que assume grande relevância no cenário atual marcado por expressivas crises no tocante ao ambiente. Ela se volta para questões do presente com vistas a um futuro melhor e possível.

A presente obra é útil para os estudiosos do Direito Ambiental, juristas e operadores do Direito. Sua temática é abordada de forma clara e coesa, o que facilita a leitura e compreensão da obra. O tema é instigante e oportuno, sobretudo porque ressalta a questão da responsabilidade civil ambiental no viés da figura do proprietário. Analisa também o nexo de causalidade, elemento da responsabilidade civil ambiental que apresenta polêmica e divisão doutrinária no que diz respeito à sua flexibilização e necessidade de prova.

Patrícia FagaIglecias Lemos é Professora Associada do Departamento de Direito Civil da Faculdade de Direito da USP. Possui Livre-Docência (2011), Doutorado (2007) e Mestrado (2002) pela mesma instituição. Orientadora dos cursos de mestrado e doutorado da Faculdade de Direito da USP e do PROCAM- Programa de Ciência Ambiental da USP. Atualmente, é pesquisadora líder do Grupo de Estudos Aplicados ao Meio Ambiente: tutelas preventiva e reparadora de danos (USP), cadastrado no CNPq.

Atua nas seguintes áreas: consumo sustentável; logística reversa; resíduos sólidos e responsabilidade civil pós-consumo; responsabilidade compartilhada; nexo de causalidade; áreas contaminadas; responsabilidade 
civil por danos ao meio ambiente; compensação ambiental.

Conferencista no Brasil e no exterior, possui diversas obras publicadas, com destaque para o livro "Resíduos sólidos e responsabilidade civil pós-consumo", pela Editora Revista dos Tribunais. Vice-Presidente para a Região Sudeste do Instituto O Direito por um Planeta Verde. Coordenadora, para o Estado de São Paulo, da Associação dos Professores de Direito Ambiental do Brasil-APRODAB. Membro do CERSOL- Centro Multidisciplinar de Estudos em Resíduos Sólidos da USP. Membro da European Environmental Law Association. Secretária de Estado do Meio Ambiente de São Paulo desde janeiro de 2015.

Como citar: SILVA, Larissa Gabrielle Braga e. Meio ambiente e responsabilidade civil do proprietário: análise do nexo causal. Scientia Iuris, Londrina, v. 20, n. 3, p.330-337, nov. 2016. DOI: 10.5433/2178-8189.2016v20n3p330. ISSN: 2178-8189.

Submetido em 18/02/2016

Aprovado em 20/10/2016 